\title{
Are Surgeons in India prepared for COVID-19?
}

\section{Kaushik Bhattacharya ${ }^{1}$}

Received: 31 March 2020 / Accepted: 6 April 2020/Published online: 17 April 2020

(C) Association of Surgeons of India 2020

\section{Dear Sir,}

SARS-COV 2, the virus responsible for Corona virus 2019 (COVID-19), has caused a global pandemic and is slowly infecting thousands in India currently and becoming a challenge for the surgeons. Given the number of surgeries done in India, it is mandatory for the surgical team to be adequately protected from virus transmission during the COVID-19 outbreak. If there is a lack or leak anywhere in the protocol, not many surgeons in India can be forced into quarantine during such crisis so there should be few mandatory precautions for the safety in the operation theatre (OT).

1. There should be a universal transport protocol for bringing COVID-19 patient to the hospital to reduce the exposure to the paramedics and the surgical team.

2. There should be an OT dedicated only for COVID -19 cases, preferably situated in a corner of the hospital complex. OT with negative pressure capabilities is recommended, to decrease the contamination of the neighbouring OT. The path of the patient to and from the OT should be kept clear. A high frequency of air changes ( 25 per hour) rapidly reduces the viral load in the OT. OT should have its own ventilation system with an integrated high-efficiency particulate air filter (HEPA) [1].

3. Traffic and flow of contaminated air should be minimised by locking all doors of the OT during surgery, with only one possible route for entry/exit via the scrub room. During the procedure, a runner is stationed outside the OT if additional drugs or equipment are needed.

Kaushik Bhattacharya

kbhattacharya10@yahoo.com

1 CAPFs Composite Hospital Border Security Force Kadamtala, G 616 Neelavatika, Uttorayon, Matigara, Siliguri, West Bengal 734010, India
4. No excessive movement allowed inside the OT. All single-use equipment (even unopened) in the room should be discarded after the OT. Therefore, it is essential that what is required in the surgical procedure should only be displayed. There should be a 30-min interval between the consecutive cases in the same OT [2].

5. All electronic gadgets like pagers, laptop or mobile and hospital case sheets should be left outside the OT. Disposable pens are to be used.

6. Donning and doffing of personal protective equipment (PPE) should be done under supervision and with utmost care. Standard PPE includes a face shield, mask, waterproof gown, double gloves and shoe covers. There is a controversy whether N 95 mask or a standard surgical mask need to be used.

7. Informed consent and charting intraoperative period are done electronically. In patients confirmed to have COVID-19 who require urgent surgery, the risk and benefit of proceeding or postponing need to be weighted.

8. Anaesthesia monitor should be covered with a plastic wrap. The number of staff in and out of the OT should be limited.

9. In COVID-19 patients, regional anaesthesia is preferred over general anaesthesia. Before the start of each operation, the anaesthesiologist puts all the drugs and equipment required for the procedure into a tray to avoid handling of the drug trolley during the case. After the surgery, the anaesthetic breathing circuit and the cannister of soda lime are discarded immediately.

10. All the surfaces of medical devices are cleaned with quaternary ammonium chloride disinfectant. The OT is cleaned with sodium hypochlorite $1000 \mathrm{ppm}$ and treated with hydrogen peroxide vaporisation or ultraviolet $\mathrm{C}$ irradiation.

11. During laparoscopy, $\mathrm{CO}_{2}$ insufflation and the use of diathermy or harmonic scalpel generate significant aerosols which may be released when pneumoperitoneum is released. Therefore, laparoscopic procedures need to be avoided in COVID-19 patients. The power setting of 
electrocautery should be as low as possible. Avoid coagulation of the same spot for a long time to reduce the surgical smoke. Spanish Association of Coloproctology suggested intracorporeal over extracorporeal anastomosis to avoid contamination with a faecal aerosol. Liberal use of suction device to remove smoke and aerosol during operation is a must especially before converting laparoscopy to open procedure [3].

12. No visitor or accompanying person are allowed in the hospital and all the shop, restaurant and facilities should remain closed.

13. Telemedicine consultation is recommended for the patient postop with the surgeon in order to reduce the hospital visits. In India, WhatsApp or mobile consultation is more feasible.

The surgeons in India should be prepared to face this challenge and I am sure that we shall overcome one day.

\section{Compliance with Ethical Standards}

Conflict of Interest The author declares that he has no conflict of interest.

\section{References}

1. Spinelli A, Pellino G (2020) Covid-19 pandemic: perspective on an unfolding crisis. Br J Surg. https://doi.org/10.1002/bjs.11627

2. Ti LK, Ang LS, Foong TW (2020) What we do when a COVID-19 patient needs an operation: operating room preparation and guidance. Can J Anesth:1-3. https://doi.org/10.1007/s12630-020-01617-4

3. Pellino G, Spinelli A (2020) How COVID-19 outbreak is impacting colorectal cancer patients in Italy: a long shadow beyond infection. Dis Colon Rectum. https://doi.org/10.1097/DCR. 0000000000001685

Publisher's Note Springer Nature remains neutral with regard to jurisdictional claims in published maps and institutional affiliations. 